\title{
Hypomethylation of proximal CpG motif of interleukin-10 promoter regulates its expression in human rheumatoid arthritis
}

\author{
Li-hong FU, Chun-ling MA, Bin CONG* ${ }^{*}$ Shu-jin LI, Hai-ying CHEN, Jing-ge ZHANG \\ Department of Forensic Medicine, Hebei Key Laboratory of Forensic Medicine, Hebei Medical University, Shijiazhuang 050017, China
}

\begin{abstract}
Aim: The promoter of human interleukin-10 (IL10), a cytokine crucial for suppressing inflammation and regulating immune responses, contains an interspecies-conserved sequence with CpG motifs. The aim of this study was to investigate whether methylation of CpG motifs could regulate the expression of ILIO in rheumatoid arthritis (RA).

Methods: Bioinformatic analysis was conducted to identify the interspecies-conserved sequence in human, macaque and mouse IL10 genes. Peripheral blood mononuclear cells (PBMCs) from 20 RA patients and 20 health controls were collected. The PBMCs from 6 patients were cultured in the presence or absence of 5-azacytidine $(5 \mu \mathrm{mol} / \mathrm{L})$. The mRNA and protein levels of IL10 were examined using RT-PCR and ELISA, respectively. The methylation of CpGs in the IL10 promoter was determined by pyrosequencing. Chromatin immunoprecipitation (ChIP) assays were performed to detect the cyclic AMP response element-binding protein (CREB)-DNA interactions.

Results: One interspecies-conserved sequence was found within the IL10 promoter. The upstream CpGs at -408, -387, -385, and -355 bp were hypermethylated in PBMCs from both the RA patients and healthy controls. In contrast, the proximal CpG at -145 was hypomethylated to much more extent in the RA patients than in the healthy controls $(P=0.016)$, which was correlated with higher IL10 mRNA and serum levels. In the 5-azacytidine-treated PBMCs, the CpG motifs were demethylated, and the expression levels of IL10 mRNA and protein was significantly increased. CHIP assays revealed increased phospho-CREB binding to the IL10 promoter. Conclusion: The methylation of the proximal CpGs in the IL10 promoter may regulate gene transcription in RA.
\end{abstract}

Keywords: rheumatoid arthritis; interleukin-10; DNA methylation; promoter regions; interspecies-conserved sequence; CpG motif; cyclic AMP response element-binding protein; bioinformatics

Acta Pharmacologica Sinica (2011) 32: 1373-1380; doi: 10.1038/aps.2011.98; published online 10 Oct 2011

\section{Introduction}

Rheumatoid arthritis (RA) is an inflammatory and autoimmune disease ${ }^{[1]}$. Proinflammatory and anti-inflammatory cytokines are involved in the initiation and progression of RA; therefore, a detailed study of the regulatory mechanism of the production of cytokines during the development of RA is of utmost importance. Interleukin-10 (IL10), produced mainly by monocytes, T helper type 2 (Th2) and regulatory T cells (Treg), plays a crucial role in suppressing inflammation and regulating the immune response ${ }^{[2]}$. It contributes to the growth and differentiation of $\mathrm{B}$ cells, but inhibits $\mathrm{T}$ cell proliferation. IL10 can fight inflammation by down-regulating the production of proinflammatory cytokines, such as tumor necrosis factor alpha (TNFa), interleukin-1 beta (IL1 $\beta$ ), interleukin-6

\footnotetext{
* To whom correspondence should be addressed.

E-mail hbydcongbin@126.com

Received 2010-12-24 Accepted 2011-06-21
}

(IL6), and others; it also stimulates the production of cytokine inhibitors (eg, the IL1 receptor antagonist and the soluble TNF receptor). Evidence has indicated that IL10 is involved in the pathogenesis of RA. Several murine models of RA are markedly exacerbated in IL10-deficient mice ${ }^{[3,4]}$. Exogenous IL10 can prevent the development of arthritis and regulate immune cell function ${ }^{[5,6]}$.

The IL10 gene exhibits substantial polymorphism in the promoter region that correlates with transcription. Recent studies have found that the methylation status of $\mathrm{CpG}$ sites is related to cytokine expression ${ }^{[7]}$. Therefore, the extent of methylation at CpG sites correlates with the level of cytokine production. Furthermore, the amount of methylation at CpG sites has been shown to be related to cells' differentiation or activation. Several CNS regions in the IL10 gene have been identified by bioinformatic analysis, including the 5 '-proximal region, promoter, and introns ${ }^{[8]}$, and the hypomethylation of CpGs around intron 4 may enhance the expression of $I L 10^{[9]}$. 
However, a correlation was not found between the CpG methylation status of the IL10 promoter and IL10 production. IL10's promoter region contains many CpGs and putative transcription factors binding sites, such as Sp-1, CCAAT/enhancer binding protein (C/EBP- $\beta$ ) and cyclic AMP response elementbinding protein (CREB). Several papers reported that the activated cAMP/CREB signaling pathway could enhance the IL10 production in human monocytes, and IFN-gamma suppressed IL10 synergize by regulating CREB/AP-1 protein expression ${ }^{[10,}$ 11]. CREB is expressed at a higher level in the synovial cells of patients with RA, and it is implicated in IL6 production from synovial cells ${ }^{[12]}$. However, whether the methylation status of a single CpG site in the IL10 promoter can regulate its transcription through affecting CREB's binding to this region in RA remains unclear. Some epigenetic clues to RA have been revealed. Global hypomethylation of the T cell genome ${ }^{[13]}$ and methylation of the death receptor 3 gene $(D R 3)^{[14]}$ and the IL6 promoter are related to the pathogenesis of $\mathrm{RA}^{[15]}$. Because epigenetic alterations are reversible, they may provide new molecular targets for therapeutic intervention. Therefore, by bioinformatics analysis, we analyzed the human IL10 gene to seek CNS and CRE. Then, we investigated whether methylation of the IL10 promoter could regulate its expression. Furthermore, we studied whether DNA methylation had an effect on CREB binding to the promoter, thus illustrating the mechanism underlying the regulatory effects of DNA methylation on gene expression.

\section{Materials and methods}

\section{Patients and controls}

Peripheral blood from 20 patients with active RA and 20 healthy controls (HCs) were studied. RA patients recruited from the Second and Third Affiliated Hospitals of Hebei Medical University (Shijiazhuang, China) were in conformity with the American College of Rheumatology Criteria ${ }^{[16]}$. Research ethics approval was obtained from Hebei Medical University Research Ethics Committee (Shijiazhuang, China), and informed consent was obtained from individual patients. Healthy controls were collected from Hebei Province Blood Center. Of the RA patients, 4 were male, and 16 were female with their mean \pm SD age being $39.6 \pm 11.4$ years old (ranging from 20 to 58 years old). Most of the RA patients in this study were in moderate disease activity. The mean DAS28 was $4.38 \pm 1.8$ (range 1.9-8.8), the mean time from onset was $25.33 \pm 22.33$ months (ranging from 3 months to 6 years), the mean erythrocyte sedimentation rate (ESR) was $37.4 \pm 28.13$ $\mathrm{mm} / \mathrm{h}$ (range 6-123), the mean C-reactive protein (CRP) was $17.27 \pm 20.63 \mathrm{mg} / \mathrm{L}$ (range 1.96-92.9), and the mean rheumatoid factor $(\mathrm{RF})$ was $164.16 \pm 122.92 \mathrm{U} / \mathrm{mL}$ (range 17.2-447). Of the healthy individuals, 4 were male, and 16 were female. Their mean \pm SD age was $38.4 \pm 10.2$ years old (ranging from 18 to 56 years old).

Peripheral blood mononuclear cells (PBMCs) and cell culture PBMCs were isolated by Ficoll-Hypaque centrifugation from peripheral blood of RA patients and HCs. PBMCs from six patients and controls were cultured in RPMI-1640 medium supplemented with $25 \mathrm{mmol} / \mathrm{L}$ HEPES, $4 \mathrm{mmol} / \mathrm{L} \mathrm{L-glu-}$ tamine, 100 units/ $\mathrm{mL}$ penicillin/streptomycin, and $5 \%$ heatinactivated fetal calf serum with $1 \mu \mathrm{g} / \mathrm{mL}$ phytohemagglutinin (PHA; Sigma, USA) and $10 \mu \mathrm{g} / \mathrm{mL}$ lipopolysaccharides (LPS; Sigma, USA) . In the presence or absence of $5 \mu \mathrm{mol} / \mathrm{L}$ 5-azacytidine (5-azaC) (Sigma, USA) for $72 \mathrm{~h}, 2 \times 10^{6}$ cells/well were cultured according to Mi's method ${ }^{[17]}$.

\section{mRNA and protein expression}

After being extracted from PBMCs using TRIzol reagent (SBS, China), the RNA was reverse transcribed in the presence of $1 \times$ PCR buffer, $1 \mathrm{mmol} / \mathrm{L}$ dNTPs, 20 units AMV reverse transcriptase, 20 units RNA guard ribonuclease inhibitor and 2.5 $\mathrm{mmol} / \mathrm{L}$ random primers (SBS, China) in a final reaction volume of $20 \mu \mathrm{L}$. Reactions were conducted at $30^{\circ} \mathrm{C}$ for $10 \mathrm{~min}$ and $42^{\circ} \mathrm{C}$ for $60 \mathrm{~min}$ using a PTC-200 PCR system (MJ Research, USA). The level of IL10 mRNA transcripts was determined by semiquantitative reverse transcription polymerase chain reaction (RT-PCR). $\beta$-actin was used as the internal standard for each RT-PCR. TNFa was measured as a control for cytokine expression. The specific primers used for the amplification of IL10 were the following: forward, 5'-TCAGGGTGGCGACTCTAT-3', and reverse, 5'-TGGGCTTCTTTCTAAATCGTTC-3'; $\beta$-actin: forward, 5'-CATCCTGCGTCTGGACCT-3', and reverse, 5'-TCAGGAGCAATGATCTTG-3'; TNFa: forward, 5'-CGAGTCTGGGCAGGTCTA-3', and reverse, 5'-GTGGTGGTCTTGTTGCTTAA-3'. PCR amplification was conducted on a PTC-200 PCR system using $5 \mu \mathrm{L}$ cDNA, $1 \times$ GeneAmp PCR Gold buffer (Applied Biosystems), $1.5 \mathrm{mmol} / \mathrm{L} \mathrm{MgCl}_{2}$ (Applied Biosystems), $200 \mu \mathrm{mol} / \mathrm{L}$ dNTPs (Shanghai Sangon Biological Engineering Technology, Shanghai, China), 0.6 $\mu \mathrm{mol} / \mathrm{L}$ forward and reverse primers, 1 unit AmpliTaq Gold DNA polymerase (Applied Biosystems) in a $20 \mu \mathrm{L}$ total reaction volume. The PCR amplification conditions were denaturation for $3 \mathrm{~min}$ at $94^{\circ} \mathrm{C}$; amplification for 30 cycles of 45 s at $94^{\circ} \mathrm{C}, 45 \mathrm{~s}$ at $50^{\circ} \mathrm{C}$ for $\operatorname{IL} 10$ (or $58^{\circ} \mathrm{C}$ for $\beta$-actin, $55^{\circ} \mathrm{C}$ for TNFa), and $45 \mathrm{~s}$ at $72{ }^{\circ} \mathrm{C}$; and extension for $10 \mathrm{~min}$ at $72^{\circ} \mathrm{C}$. PCR products were resolved by $2 \%$ agarose gel electrophoresis with ethidium bromide. The images were recorded and quantified by Hema analyzer (Udine, Italy). The level of IL10 in serum was measured by ELISA (Bender MedSystems, Austria) according to the manufacturer's instructions.

\section{Bioinformatics}

Alignments between mouse and human IL10 loci, and between macaque and human IL10 loci were performed, and the extent of DNA sequence homology was computed with a web-based program called Regulatory Visualization Tools for Alignment (rVISTA; http://www.gsd.lbl.gov/vista) ${ }^{[18]}$. The plot of the percentage of sequence identity referred to the human sequence. Regions with a length of at least 100 bp, which showed at least 75 percent sequence identity at each segment of the alignment between successive gaps, are identified as CNS and are shown in Figure 1. 


\section{DNA methylation status}

DNA was extracted from the PBMCs by the phenol-chloroform method. The DNA concentration was measured by a spectrophotometer (Bio-Rad, USA). One microgram of DNA was treated with sodium bisulphite as previously described ${ }^{[19]}$. PCR and pyrosequencing primers were designed using PSQ Assay Design software (Biotage, Sweden) to amplify the CpG dinucleotides in the IL10 promoter. The primer sequences used are in Table 1. PCR was performed in a $50 \mu \mathrm{L}$ reaction system of GeneAmp 9700 (Applied Biosystems, USA). Each PCR reaction contained $50 \mathrm{ng}$ bisulfite treated DNA, $1 \times$ PCR buffer, $2.5 \mathrm{mmol} / \mathrm{L} \mathrm{MgCl}_{2}, 0.2 \mathrm{mmol} / \mathrm{L} \mathrm{dNTPs}, 0.2 \mu \mathrm{mol} / \mathrm{L}$ forward primer, $0.2 \mu \mathrm{mol} / \mathrm{L}$ reverse primer, and 1 unit AmpliTaq Gold (Applied Biosystems, USA). The PCR conditions were initiated with a heated lid at $95^{\circ} \mathrm{C}$ for $5 \mathrm{~min}$, followed by 50 cycles of $95^{\circ} \mathrm{C}$ for $15 \mathrm{~s}, 51^{\circ} \mathrm{C}$ for $30 \mathrm{~s}, 72^{\circ} \mathrm{C}$ for $30 \mathrm{~s}$, and, finally, $72^{\circ} \mathrm{C}$ for $5 \mathrm{~min}$. PCR product quality verification was performed using $2 \%$ agarose gels with ethidium bromide. Fifty microliters of PCR products was used for each pyrosequencing reaction. Pyrosequencing methylation analysis was conducted by the Pyro Q-CpG system (PyroMark ID, Biotage, Sweden) according to the manufacturer's protocol. In brief, the PCR product was bound to streptavidin-coated Sepharose beads (GE Healthcare Bio-sciences AB, Sweden). The Sepharose beads containing the immobilized PCR product were purified in $70 \%$ ethanol for $5 \mathrm{~s}$, denatured in denaturing buffer (Biotage) for $5 \mathrm{~s}$, and washed with washing buffer (Biotage) for $10 \mathrm{~s}$ using the pyrosequencing Vacuum Prep Tool (Biotage). Then, $0.5 \mu \mathrm{mol} / \mathrm{L}$ sequence primer was annealed to the purified, single-stranded PCR product, and pyrosequencing was fulfilled by the Pyro Q-CpG system. The level of methylation for each cytosine locus on $\mathrm{CpG}$ sites was expressed as the percentage of $\mathrm{mC} /(\mathrm{mC}+\mathrm{C})(\mathrm{mC}$ is methylated cytosine, $\mathrm{C}$ is unmethylated cytosine). Non-CpG cytosine residues were used as controls to verify bisulfite conversion.

Table 1. Pyrosequencing primer sequences.

\begin{tabular}{lll}
\hline $\begin{array}{l}\text { CpG } \\
\text { sites }\end{array}$ & \multicolumn{1}{c}{$\begin{array}{c}\text { PCR primer } \\
\text { sequences }\left(5^{\prime}-3^{\prime}\right)\end{array}$} & \multicolumn{1}{c}{$\begin{array}{l}\text { Sequecing primer } \\
\text { sequences }\left(5^{\prime}-3^{\prime}\right)\end{array}$} \\
\hline-408 & $\begin{array}{l}\text { TGTATTTTGGAATGGGTAATTT } \\
\text { (Biotin) AAAACCCTCAACTATAAATTCTCA }\end{array}$ & GGAATGGGTAATTTGTT \\
-387 & same to -408 & TATTGTGATTTAGGAATA \\
-385 & same to -408 & same to -387 \\
-355 & $\begin{array}{l}\text { GAATACGCGAATGAGAATTATAG } \\
\text { (Biotin)TTTCCTAAAAAACAACTATTCTA }\end{array}$ & TTTATAGTTGAGGGTTTTTG \\
-145 & $\begin{array}{l}\text { AGAAGGAGGAGTTTTAAGGAGAAA } \\
\text { (Biotin) TCATTCATTAAAAAACCACAATCA }\end{array}$ & AGGAGAAAAATTTTGTGT \\
\hline
\end{tabular}

\section{Chromatin immunoprecipitation (ChIP) assay}

According to the manufacturer's instructions, the ChIP assay was performed to detect phospho-CREB binding to the IL10 promoter in the PBMCs of patients in situ before and after
5-azaC treatment. ChIP was performed with the Chromatin Immunoprecipitation Assay Kit (Upstate Biotechnology, No 17-295) and anti-phospho-CREB antibody (Ser133) (Upstate Biotechnology, № 06-519). PCR was performed on IL10's upstream promoter and proximal promoter, and an intron was amplified as internal control. Primer sequences were upstream promoter primer sequence, forward, 5'-GAAGTCTTGGGTATTCATCC-3', reverse, 5'-GCTGTGGGTTCTCATTCG-3'; promoter primer sequence, forward, 5'-CTCCCCAGGAAATCAACT-3', reverse, 5' -AAAAGCCACAATCAAGGT-3'; intron primer sequence, forward, 5'-TTAGAGCGTTTCCAGACC-3', reverse, 5'-ACCTATGTCAACCCTTCG-3'. PCR was performed in a $20 \mu \mathrm{L}$ reaction in GeneAmp 9700 (Applied Biosystems, USA). Each PCR reaction contained $100 \mathrm{ng}$ DNA, $1 \times$ PCR buffer, $2.0 \mathrm{mmol} / \mathrm{L} \mathrm{MgCl}_{2}, 0.2 \mathrm{mmol} / \mathrm{L}$ dNTPs, 0.2 $\mu \mathrm{mol} / \mathrm{L}$ forward and reverse primers, and 1 unit AmpliTaq Gold (Applied Biosystems, USA). The PCR conditions were initiated with a heated lid at $95^{\circ} \mathrm{C}$ for $3 \mathrm{~min}$, followed by 35 cycles of $94^{\circ} \mathrm{C}$ for $45 \mathrm{~s}, 51-55^{\circ} \mathrm{C}$ for $45 \mathrm{~s}, 72^{\circ} \mathrm{C}$ for $45 \mathrm{~s}$, and, finally, $72^{\circ} \mathrm{C}$ for $5 \mathrm{~min}$. PCR products were analyzed in an agarose gel. Values were normalized according to the input.

\section{Statistical analysis}

All calculations were performed on a Microsoft computer using SPSS software (version 14.0). Data were analyzed by independent-samples $t$ test and paired $t$ test. Correlation coefficients were calculated by Pearson rank correlation $(r)$ and Spearman rank correlation where applicable.

\section{Results}

Bioinformatic approach to the identification of CREs in IL10 locus

We performed a bioinformatic search for CREs in the IL10 locus using web-based software, rVISTA. This program can identify interspecies-conserved sequences for specific transcription factors by linking to the most widely used database, TRANSFAC. As shown in Figure 1, four CREs were found between macaques and humans ranging from introns 1 to 4 and all were interspecies-conserved. As the readily available macaque IL10 sequence does not contain the upstream promoter region, we did not compare the IL10 promoter region of macaque with that of humans. Three CREs were found between mice and humans, including the 5 '-proximal region, promoter and introns 1 to 4 , and the interspecies-conserved CRE was in the promoter and a short fragment of intron 4. This suggested that the CRE in the promoter, designated as p-CRE, may be important for the regulation of IL10 gene expression.

\section{Methylation status of IL10 promoter}

There are at least five CpG sites in the IL10 promoter region, four located at $-408,-387,-385,-355 \mathrm{bp}$ (upstream) and one at $-145 \mathrm{bp}$ (proximal) relative to the transcription start site. It was found that methylation of individual CpG sites was similar in PBMCs from the $20 \mathrm{RA}$ patients and the $20 \mathrm{HCs}$; that is, the upstream CpG motifs were hypermethylated, while the 


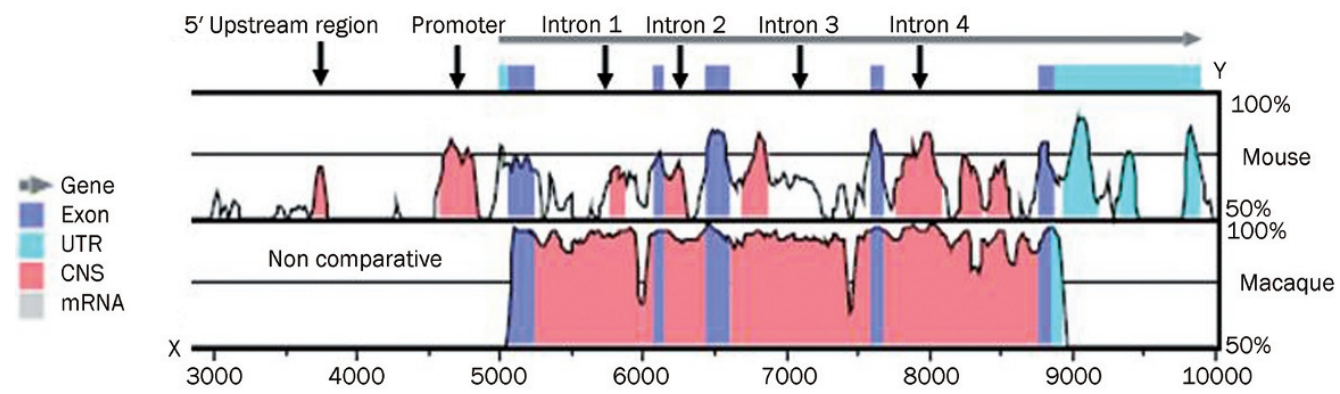

Figure 1. Bioinformatics analysis of the conserved CREs on the IL10 locus. A web-based program, rVISTA, was used to align the mouse, macaque and human IL10 loci and compute the extent of DNA sequence homology. The mouse and macaque sequences are used as the query sequences on the $y$-axis, and the human sequence is used as the subject sequence on the $x$-axis.

proximal CpG motif was hypomethylated. However, in the patients, methylation of cytosine at $-145 \mathrm{bp}$ was significantly less than that in the HCs $(18 \% \pm 7 \%$ versus $33 \% \pm 6.6 \% ; P=0.016)$ (Figure 2).

\section{Methylation status and mRNA expression}

We then studied the relationship between the methylation status of the IL10 gene and mRNA expression. The mRNA $(0.89 \pm 0.21$ versus $0.70 \pm 0.13, P=0.009)$ and serum level $(71.36 \pm 43.25 \mathrm{pg} / \mathrm{mL}$ versus $42.85 \pm 2.99 \mathrm{pg} / \mathrm{mL}, P=0.012)$ of IL10 was significantly higher in the patients than in HCs. Furthermore, IL10 mRNA levels of the patients were correlated with the RA factor $(r=0.526, P=0.016)$. As for control cytokine, TNFa mRNA expression was significantly higher in the PBMCs of RA patients than in controls $(0.5143 \pm 0.5249$ versus $0.0861 \pm 0.1434, P=0.010$ ). Compared with the $20 \mathrm{HCs}$, the methylation frequency of $-145 \mathrm{C}$ was significantly lower in the 20 RA patients, which resulted in inversely higher IL10 mRNA levels (Figure 3). Therefore, hypomethylation of $-145 \mathrm{C}$ was correlated with higher mRNA expression $(r=-0.746, P=0.001)$. Furthermore, after PBMCs from the six patients were cultured in the presence of 5-azaC, all five CpG motifs were demethylated (Table 2), and the mRNA of IL10 $(0.2866 \pm 0.15$ versus $0.4488 \pm 0.13, P=0.037)$ and protein levels $(5.30 \pm 8.48 \mathrm{pg} / \mathrm{mL}$

Table 2. Comparison of the methylation status of individual $\mathrm{CpG}$ sites in PBMCs from RA patients between 5-azaC untreated group and treated group.

\begin{tabular}{ccll}
\hline CpG sites & Untreated group & Treated group & $P$ \\
\hline-408 & $81 \% \pm 18 \%$ & $51 \% \pm 13 \%$ & 0.04 \\
-387 & $81 \% \pm 7 \%$ & $63 \% \pm 7.3 \%$ & 0.015 \\
-385 & $84 \% \pm 3.5 \%$ & $65 \% \pm 5.9 \%$ & 0.001 \\
-355 & $92 \% \pm 9.3 \%$ & $73 \% \pm 15.7 \%$ & 0.141 \\
-145 & $19 \% \pm 4 \%$ & $15 \% \pm 3.2 \%$ & 0.4 \\
\hline
\end{tabular}

A

$-408$

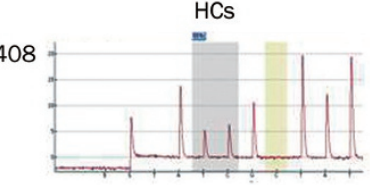

$-387$

$-385$

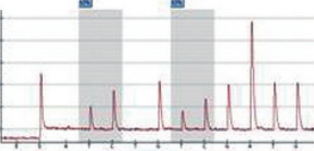

$-355$

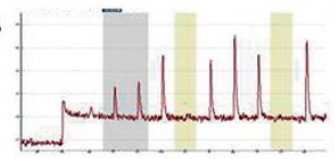

$-145$

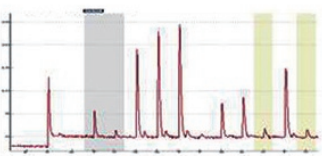

RA
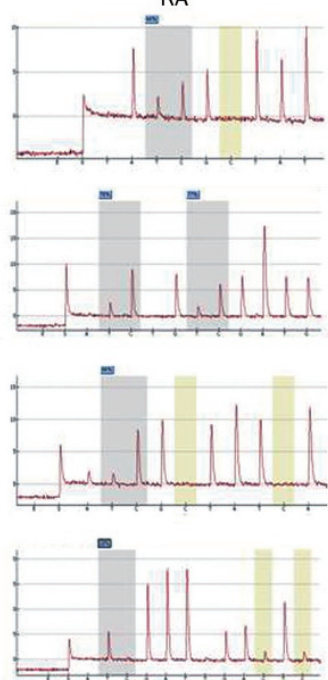

B

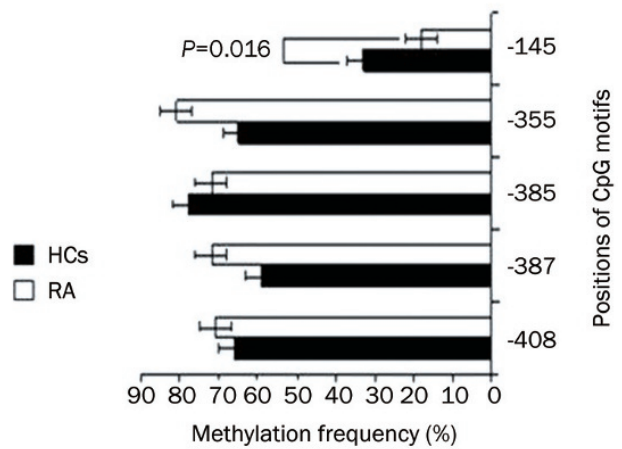

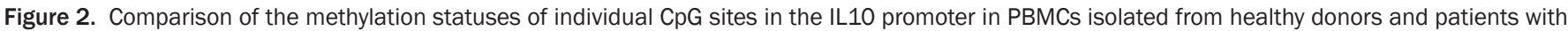

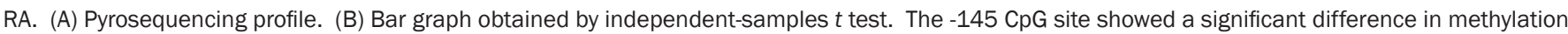

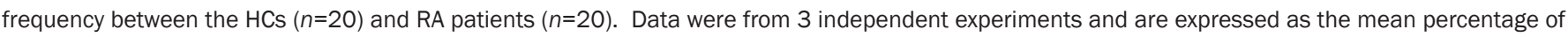
methylated CpG at each position in the IL10 promoter of the $20 \mathrm{HCs}$ and 20 RA patients. 
A

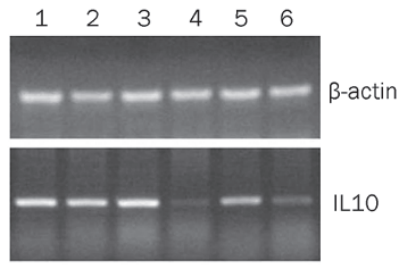

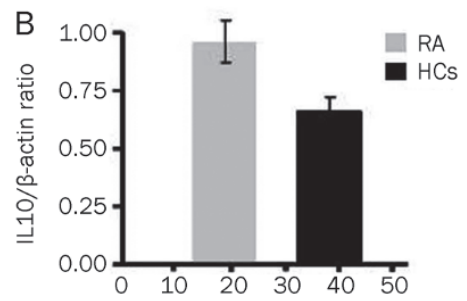

-145 CpG methylation percentage (\%)

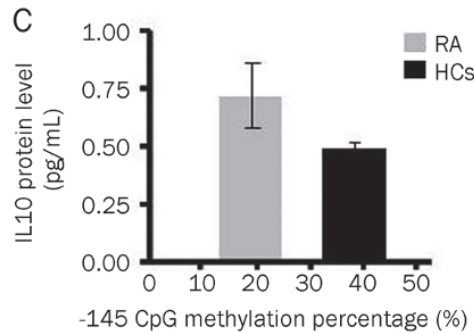

Figure 3. Comparison of the mRNA levels and $-145 \mathrm{CpG}$ methylation status of IL10 in PBMCs from RA patients and HCs. (A) IL10 mRNA expression. 1, 2, 3: RA patients; 4, 5, 6: HCs. Shown are the results from 3 representative subjects per group. (B) Correlation between -145 CpG methylation status and mRNA expression. (C) Correlation between -145 CpG methylation status and protein levels in serum. Seven milliliters of peripheral blood was collected from 20 RA patients and 20 healthy individuals, and approximately $5 \times 10^{6}-7 \times 10^{6}$ PBMCs were isolated by Ficoll-Hypaque centrifugation. RNA was extracted using TRIzol reagent. The contents of IL10 in RA patients' serum and positive control from the kit were measured by ELISA according to the manufacturer's instructions. The methylation frequency of $-145 \mathrm{CpG}$ site was lower in PBMCs from RA $(n=20)$ with higher IL10 mRNA and protein levels than $\mathrm{HCs}(n=20)$.

versus $72.00 \pm 7.12 \mathrm{pg} / \mathrm{mL}, P=0.012$ ) were increased in the presence of 5-azaC, whereas the mRNA level of $\beta$-actin and TNFa remained constant. IL10 mRNA (1 versus $1.7084 \pm 1.8361$, $P=0.47)$ and protein expressions $(1.4349 \pm 0.5887 \mathrm{pg} / \mathrm{mL}$ versus $3.275 \pm 2.0533 \mathrm{pg} / \mathrm{mL}, P=0.093)$ were increased after the control cells were treated with 5 -azaC, but the difference was not significant.

\section{Effects of methylation at IL10 CpG motifs on the binding of a transcription factor}

There are at least three possible binding sites for CREB and C/EBP family members in the IL10 promoter: one in upstream sequences at $-408 \mathrm{C}$ and the others upstream of the promoter $(-292$ to $-304 \mathrm{bp})$ or in the promoter region $(-49$ to $-59 \mathrm{bp})$. ChIP assay results showed that the density of the IL10 promoter and upstream promoter bands was significantly higher in the 5-azaC treated group than in the untreated group (Figure 4).

\section{Discussion}

In many murine models of RA, IL10 attenuated arthritis ${ }^{[5,6]}$; however, the clinical improvement of RA patients was unsta- ble $e^{[20]}$. Gene therapies have been attempted to overcome this defect. The treatment of a single joint by local delivery of the viral IL10 gene may protect multiple joints of the same mice with $\mathrm{CIA}^{[21]}$. With regard to IL10 production, Im SH et al analyzed the IL10 gene and showed that the promoter was highly conserved between humans and mice ${ }^{[22]}$. In the present study, we found one interspecies-conserved CRE within the promoter as well. Dong et $a l^{[8]}$ analyzed the CPG methylation pattern of the IL10 locus and detected two slightly demethylated CpGs in the proximal promoter in IL10 ${ }^{+}$vs IL10- Th cells. They concluded that there was no correlation between methylation pattern and IL10 expression. In contrast, our study revealed a significant methylation of p-CRE for IL10 production. Although we observed that upstream CpG motifs were highly methylated in both the patients and the HCs, the methylation levels of the $-145 \mathrm{CpG}$ site were lower than that of upstream CpG motifs in the patients and HCs and were much lower in the patients, whose IL10 mRNA and serum levels were elevated. Furthermore, the lower methylation of -145C correlated with higher mRNA levels in RA. Thus, the hypomethylation of -145C may regulate gene expression at the transcriptional level and be responsible for the development of RA
A
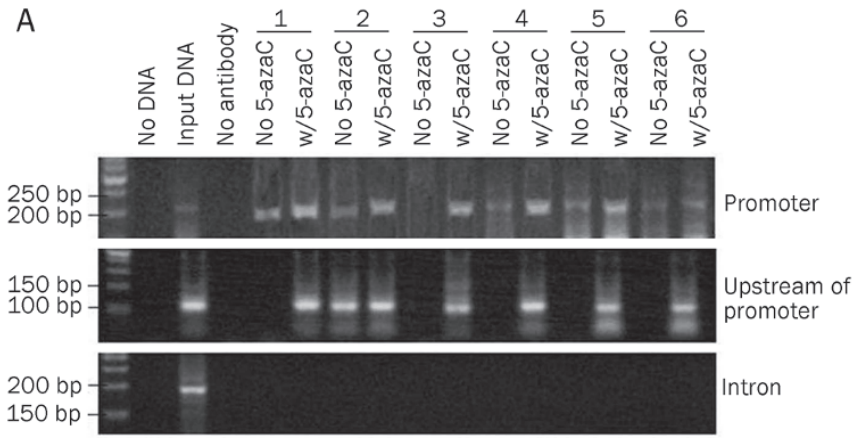

B

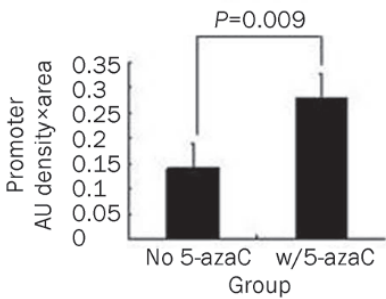

C

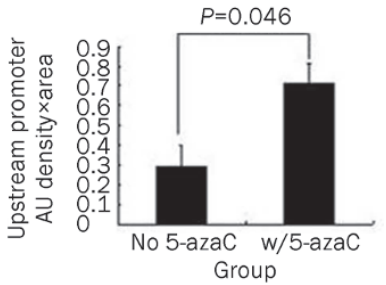

Figure 4. ChIP assays of the phospho-CREB binding within the IL10 promoter and upstream promoter region in PBMCs from the RA patients treated with or without 5-azaC. (A) ChIP assay results. Each sample has its own input DNA, and this picture displays the first sample only. (B) Relative levels of PCR products analyzed by Gel-pro analyzer software. Data stemmed from 3 independent experiments and are presented as the mean \pm SD of 6 RA patients. A paired-samples $T$ test was performed. No 5-azaC: without 5-azaC treatment. w/5-azaC: with 5-azaC treatment. 
in some people.

IL10 is produced mainly by monocytes, B cells, Th2, and Treg. PBMCs are a mixture of a variety of cells, including $\mathrm{T}$ cells, B cells, and monocytes. The cells in the peripheral blood interregulate each other's function through their secreted cytokines, which form a complicated network. Measuring the mRNA level of IL10 in PBMCs and the protein level in serum could reflect the general IL10 expression status and the interregulation among cells. In this study, we detected higher IL10 mRNA and protein levels in RA patients than in controls, which may be related to patients' varied disease activities and treatment statuses, and this finding is consistent with other reports in the field ${ }^{[23-25]}$. For example, Iwata et al ${ }^{[23]}$ reported that the mean B10 + progenitor B10 (B10pro) cell frequencies were significantly higher in patients with RA compared with healthy controls. Additionally, IL10 production by blood B cells has been reported to be higher in patients with $\mathrm{RA}^{[24]}$. Sempere-Ortells et $a l^{[25]}$ found increased IL10 and a higher proportion of CD4(+)IL10(+), CD4(+)CD25(int)IL10(+) cells in peripheral blood of patients with moderately active disease. Taken together, these findings suggested that during active disease, these cell subsets produce progressively larger amounts of IL10 to regulate inflammation in response to the activity of the disease. The demethylation of $-145 \mathrm{CpG}$ in the IL10 promoter could elevate its mRNA expression, which may ameliorate the symptoms of RA. In this paper, we completed a preliminary study of the IL10 expression and promoter methylation status from the peripheral blood of RA patients. Further study is needed on the regulation mechanisms of all IL10-secreting cells after the separation and purification of individual cell lineages.

Nile $e t a l^{[15]}$ found that the differences identified between RA patients and healthy individuals could either be a primary phenomenon, implying that lower methylation at IL6 -1099C is inversely correlated with development of RA or are secondary to the disease process or treatment. It was found in our study that lower methylation of IL10 -145C might lead to similar results. Medications such as corticosteroids can alter lymphocyte trafficking and cause relative lymphopenia ${ }^{[26]}$. It is increasingly recognized that glucocorticoids change chromatin structure ${ }^{[27]}$. Glucocorticoids may lead to the deacetylation of histones, resulting in the tighter coiling of DNA and reduced access of transcription factors to their binding sites, thereby suppressing the activity of DNA methyltransferases. Methotrexate therapy has been associated with increased DNA methylation ${ }^{[28]}$. Participants in our study had not used any of these treatments or other immunosuppressants for 3 months before enrollment in the study. Ibuprofen, nimesulide and diclofenac sodium enteric-coated tablets were used to help patients reduce inflammation and pain, and these therapies have no effect on DNA methylation. DNA methyltransferase activity is proliferation dependent and cell cycle regulated ${ }^{[29,30]}$. Thus, any therapy that affects proliferation and interferes with DNA methyltransferase activity may affect the status of DNA methylation, but further study is needed to confirm this. Prospective studies of patients with recent-onset
RA will be required to elucidate the potential affects of drugs on DNA methylation.

Epigenetic alterations are reversible, providing new molecular targets for therapy. 5-azaC is an inhibitor of DNA methyltransferases. In this study, 5-azaC induced demethylation of the upstream and proximal CpG sites, and IL10 mRNA expression increased in PBMCs of the patient. Thus, this experiment may contribute to overcoming the relative deficiency of IL10 in RA patients and be hopeful for changing RA progression. To test whether methylation of the $\mathrm{CpG}$ motifs can inhibit transcription factor binding, we performed ChIP assays. Several transcription factors, such as GRE, CREB, Sp1, and C/EBPs, can bind to the IL10 promoter. It was reported that cAMP/CREB signaling was involved in IL10 transcription in human monocytic cells ${ }^{[11]}$, and C/EBP and CREB/ATF were activated as well. CREB, a member of the leucine zipper family of transcription factors, can be activated by phosphorylation at serine residue 133 (Ser-133) and further induces transcription of genes in response to the cAMP pathway. $\mathrm{C} / \mathrm{EBPs}$, another member of the leucine zipper family, contain at least six members (C/EBP alpha to $C / E B P$ zeta). C/EBP $\beta$ has been shown to interact with CREB/ATF ${ }^{[31]}$. Therefore, an antibody specific for phospho-CREB can be combined with phospho-CREB-DNA and the CREB/ATF-C/EBP $\beta$-DNA compound. Our results indicated that 5 -azaC treatment increased CREB and/or C/EBP $\beta$ binding to the region upstream of the promoter and to the promoter region, which was consistent with demethylated CpGs and increased mRNA expression. $-408 \mathrm{C}$ was contained in CREB and C/EBP $\beta$ binding sequences, and the result indicated its methylation inhibited CREB and $\mathrm{C} / \mathrm{EBP} \beta$ binding to the upstream promoter directly. All other CpG motifs were also demethylated (Table 1). Therefore, simultaneous demethylation of upstream and proximal $\mathrm{CpG}$ motifs in the IL10 promoter may allow easier access for transcription factors to their binding sites, thus enhancing IL10 transcription. Other transcription factors, aside from CREB, may participate in the regulation of the IL10 gene, such as $\mathrm{STAT}^{[32]}$, another transcription factor that binds near -145 , NF-kB, and GRE. Whether the other transcription factors' binding activities are regulated by DNA methylation remains to be investigated.

Until now, there have been very limited data regarding the epigenetic regulation of genes in RA; only the methylation status of $D R 3^{[14]}$ and $I L 6^{[15]}$ was reported. The histone deacetylase activity in synovial tissues from patients with RA was approximately 2-fold lower than that in synovial tissues from patients with osteoarthritis or from normal controls ${ }^{[33]}$. A single intravenous injection of depsipeptide (FK228), a histone deacetylase inhibitor, inhibited joint swelling, synovial inflammation and subsequent bone and cartilage destruction in mice with autoantibody-mediated arthritis (AMA) ${ }^{[34]}$. The authors also found that intravenous treatment with FK228 induced the hyperacetylation of histone $\mathrm{H} 3$ and $\mathrm{H} 4$ in synovial cells. Furthermore, histone deacetylase inhibitor, trichostatin A (TSA), in combination with ultrasound, effectively reduces cell viability and induces apoptosis in the RASFs of RA patients ${ }^{[35]}$. 
Analysis of the genes that are epigenetically regulated in RA, taking into account not only DNA methylation but also histone modifications, is worth exploring.

In summary, we found that the proximal CpG motif $-145 \mathrm{C}$ in the IL10 promoter region was hypomethylated in RA PBMCs, which may regulate gene transcription and be responsible for the pathogenesis of RA. The demethylation of CpG motifs within the IL10 promoter contributes to its overexpression; thus, demethylation may remedy the relative deficiency of IL10 in RA patients and may be a new therapeutic strategy in the treatment of RA.

\section{Acknowledgements}

Our sincere thanks go to Mr Jian-gang WEI, PhD candidate of Shandong University, China, for his proofreading of the paper. Our work is supported by the National Natural Science Foundation of China (grant 30770839) and the Hebei Province Natural Science Foundation of China (grant 30100154). We are grateful to the Second and Third Affiliated Hospitals of Hebei Medical University for recruiting the RA patient samples.

\section{Author contribution}

Bin CONG designed the study; Li-hong FU and Hai-ying CHEN performed the research; Chun-ling MA and Jing-ge ZHANG contributed new reagents or analytic tools; Li-hong FU and Shu-jin LI analyzed data; and Li-hong FU wrote the paper.

\section{References}

1 Choy EH, Panayi GS. Cytokine pathways and joint inflammation in rheumatoid arthritis. N Engl J Med 2001; 344: 907-16.

2 Keystone E, Wherry J, Grint P. IL-10 as a therapeutic strategy in the treatment of rheumatoid arthritis. Rheum Dis Clin North Am 1998; 24: 629-39.

3 Finnegan A, Kaplan CD, Cao Y, Eibel H, Glant TT, Zhang J. Collageninduced arthritis is exacerbated in IL-10-deficient mice. Arthritis Res Ther 2003; 5: R18-24.

4 Johansson AC, Hansson AS, Nandakumar KS, Bäcklund J, Holmdahl R. IL-10-deficient B10.Q mice develop more severe collagen-induced arthritis, but are protected from arthritis induced with anti-type II collagen antibodies. J Immunol 2001; 167: 3505-12.

5 Dai Q, Li Y, Zhang F, Yu H, Wang X. Therapeutic effect of low-dose IL-18 combined with IL-10 on collagen-induced arthritis by downregulation of inflammatory and Th1 responses and induction of Th2 responses. Rheumatol Int 2009; 29: 615-22.

6 Choi JJ, Yoo SA, Park SJ, Kang YJ, Kim WU, Oh IH, et al. Mesenchymal stem cells overexpressing interleukin-10 attenuate collagen-induced arthritis in mice. Clin Exp Immunol 2008; 153: 269-76.

7 Fitzpatrick DR, Wilson CB. Methylation and demethylation in the regulation of genes, cells, and responses in the immune system. Clin Immunol 2003; 109: 37-45.

8 Dong J, Ivascu C, Chang HD, Wu P, Angeli R, Maggi L, et al. IL-10 is excluded from the functional cytokine memory of human $C D 4^{+}$ memory T lymphocytes. J Immunol 2007; 179: 2389-96.

9 Tsuji-Takayama K, Suzuki M, Yamamoto M, Harashima A, Okochi A, Otani $\mathrm{T}$, et al. The production of IL-10 by human regulatory $\mathrm{T}$ cells is enhanced by IL-2 through a STAT5-responsive intronic enhancer in the IL-10 locus. J Immunol 2008; 181: 3897-905.
10 Gee K, Angel JB, Ma W, Mishra S, Gajanayaka N, Parato K, et al. Intracellular HIV-Tat expression induces IL-10 synthesis by the CREB-1 transcription factor through Ser133 phosphorylation and its regulation by the ERK1/2 MAPK in human monocytic cells. J Biol Chem 2006; 281: 31647-58.

11 Hu X, Paik PK, Chen J, Yarilina A, Kockeritz L, Lu TT, et al. IFN-gamma suppresses IL-10 production and synergizes with TLR2 by regulating GSK3 and CREB/AP-1 proteins. Immunity 2006; 24: 563-74.

12 Ishizu A, Abe A, Miyatake Y, Baba T, linuma C, Tomaru U, et al. Cyclic AMP response element-binding protein is implicated in IL-6 production from arthritic synovial cells. Mod Rheumatol 2010; 20: 134-8.

13 Richardson B, Scheinbart L, Strahler J, Gross L, Hanash S, Johnson M. Evidence for impaired T cell DNA methylation in systemic lupus erythematosus and rheumatoid arthritis. Arthritis Rheum 1990; 33: 1665-73.

14 Takami N, Osawa K, Miura Y, Komai K, Taniguchi M, Shiraishi M, et al. Hypermethylated promoter region of DR3, the death receptor 3 gene, in rheumatoid arthritis synovial cells. Arthritis Rheum 2006; 54 : 779-87.

15 Nile CJ, Read RC, Akil M, Duff GW, Wilson AG. Methylation status of a single CpG site in the IL6 promoter is related to IL6 messenger RNA levels and rheumatoid arthritis. Arthritis Rheum 2008; 58: 2686-93.

16 Arnett FC, Edworthy SM, Bloch DA, McShane DJ, Fries JF, Cooper NS, et al. The American rheumatoid association 1987 revised criteria for the classification of rheumatoid arthritis. Arthritis Rheum 1988; 31 : 315-24.

$17 \mathrm{Mi}$ XB, Zeng FQ. Hypomethylation of interleukin-4 and -6 promoters in $T$ cells from systemic lupus erythematosus patients. Acta Pharmacol Sin 2008; 29: 105-12.

18 Loots GG, Ovcharenko I. rVISTA 2.0: evolutionary analysis of transcription factor binding sites. Nucleic Acids Res 2004; 32: W217-21.

19 Clark SJ, Harrison J, Paul CL, Frommer M. High sensitivity mapping of methylated cytosines. Nucleic Acids Res 1994; 22: 2990-7.

20 van Roon JA, Bijlsma JW, Lafeber FP. Suppression of inflammation and joint destruction in rheumatoid arthritis may require a concerted action of Th2 cytokines. Curr Opin Investig Drugs 2002; 3: 1011-6.

21 Whalen JD, Lechman EL, Carlos CA, Weiss K, Kovesdi I, Glorioso JC, et al. Adenoviral transfer of the viral IL10 gene periarticularly to mouse paws suppresses development of collagen-induced arthritis in both injected and uninjected paws. J Immunol 1999; 162: 3625-32.

22 Im SH, Hueber A, Monticelli S, Kang KH, Rao A. Chromatin-level regulation of the IL10 gene in T cells. J Biol Chem 2004; 279: 46818-25.

23 Iwata Y, Matsushita T, Horikawa M, Dilillo DJ, Yanaba K, Venturi GM, et al. Characterization of a rare IL-10-competent B-cell subset in humans that parallels mouse regulatory B10 cells. Blood 2011; 117: 530-41.

24 Llorente L, Richaud-Patin Y, Fior R, Alcocer-Varela J, Wijdenes J, Fourrier BM, et al. In vivo production of interleukin-10 by non-T cells in rheumatoid arthritis, Sjogren's syndrome, and systemic lupus erythematosus: a potential mechanism of B lymphocyte hyperactivity and autoimmunity. Arthritis Rheum 1994; 37: 1647-55.

25 Sempere-Ortells JM, Pérez-García V, Marín-Alberca G, Peris-Pertusa A, Benito JM, Marco FM, et al. Quantification and phenotype of regulatory $T$ cells in rheumatoid arthritis according to disease activity score-28. Autoimmunity 2009; 42: 636-45.

$26 \mathrm{Xu}$ J, Winkler J, Sabarinath SN, Derendorf H. Assessment of the impact of dosing time on the pharmacokinetics/pharmacodynamics of prednisolone. AAPS J 2008; 10: 331-41.

27 Archer TK, Deroo BJ, Fryer CJ. Chromatin modulation of glucocorticoid and progesterone receptor activity. Trends Endocrinol Metab 1997; 8: 
384-90.

28 Kim YI, Logan JW, Mason JB, Roubenoff R. DNA hypomethylation in inflammatory arthritis: reversal with methotrexate. J Lab Clin Med 1996; 128: 165-72.

29 Issa JP, Vertino PM, Wu J, Sazawal S, Celano P, Nelkin BD, et al. Increased cytosine DNA-methyltransferase activity during colon cancer progression. J Natl Cancer Inst 1993; 85: 1235-40.

30 Robertson KD, Keyomarsi K, Gonzales FA, Velicescu M, Jones PA. Differential mRNA expression of the human DNA methyltransferases (DNMTs) 1 , $3 a$ and $3 b$ during the $G_{0} / G_{1}$ to $S$ phase transition in normal and tumor cells. Nucleic Acids Res 2000; 28: 2108-13.

31 Ramji DP, Foka P. CCAAT/enhancer-binding proteins: structure, function and regulation. Biochem J 2002; 365: 561-75.

32 Benkhart EM, Siedlar M, Wedel A, Werner T, Ziegler-Heitbrock HW.
Role of Stat3 in lipopolysaccharide-induced IL-10 gene expression. J Immunol 2000; 165: 1612-7.

33 Huber LC, Brock M, Hemmatazad H, Giger OT, Moritz F, Trenkmann M, et al. Histone deacetylase/acetylase activity in total synovial tissue derived from rheumatoid arthritis and osteoarthritis patients. Arthritis Rheum 2007; 56: 1087-93.

34 Nishida K, Komiyama T, Miyazawa S, Shen ZN, Furumatsu T, Doi H, et al. Histone deacetylase inhibitor suppression of autoantibodymediated arthritis in mice via regulation of p16INK4a and p21 $1^{\text {WAF } 1 / \text { Cip } 1}$ expression. Arthritis Rheum 2004; 50: 3365-76.

35 Nakamura C, Matsushita I, Kosaka E, Kondo T, Kimura T. Anti-arthritic effects of combined treatment with histone deacetylase inhibitor and low-intensity ultrasound in the presence of microbubbles in human rheumatoid synovial cells. Rheumatology (Oxford) 2008; 47: 418-24. 